http://jmscr.igmpublication.org/home/

ISSN (e)-2347-176x ISSN (p) 2455-0450

crossref DOI: https://dx.doi.org/10.18535/jmscr/v7i7.161

Journal Of Medical Science And Clinical Research

\title{
Rhinosporidiosis of Parotid Duct: An Atypical Presentation
}

\author{
Authors \\ Samira Kumar Behera ${ }^{1}$, Shushruta Mohanty*2, Sujit Manohar Swain ${ }^{3}$, Biswajit Padhy ${ }^{4}$ \\ ${ }^{1}$ Associate Professor, Dept of Pathology, S.L.N.M.C, Koraput, Odisha \\ ${ }^{2}$ Senior Resident, Dept of Pathology, M.K.C.G, M.C.H, Berhampur, Odisha \\ ${ }^{3,4}$ Post Graduates, Dept of Pathology, M.K.C.G M.C.H, Berhampur, Odisha \\ *Corresponding Author \\ Dr Shushruta Mohanty
}

Senior Resident, Dept of Pathology, M.K.C.G M.C.H, Berhampur, Odisha

\begin{abstract}
Rhinosporidiosis is a chronic granulomatous infective disease caused by fungi, Rhinosporidium seeberi. It occurs universally and is endemic in India, Sri Lanka and in South Asia. Rhinosporidiosis classically involves anterior nares, nasal cavity, nasopharynx, larynx and soft palate and presents as a localized polypoid mass. However Rhinosporidiosis involving parotid duct is rare. The case discussed here is of a 55-year-old male who presented with a sudden onset of unilateral facial swelling associated with on and off pain during mastication. Cytological findings was inconclusive and was suggestive of retention cyst. Although rhinosporidiosis was not taken into consideration in the clinical differential diagnosis, histopathological diagnosis confirmed the case to be rhinosporidiosis.

Keyword: Parotid duct, Rhinosporidiosis.
\end{abstract}

\section{Introduction}

Rhinosporidiosis is a benign chronic granulomatous disease caused by Rhinosporidium seeberi ${ }^{[1]}$. Although rhinosporidiosis occurs universally with higher occurrence in parts of South Asia, it is endemic, especially in Southern India and Sri Lanka ${ }^{[2-4]}$. Nasal cavity is the most common site of infection ${ }^{[1]}$. Other sites affected includes the nasopharynx, larynx, oropharynx, conjunctiva, lacrimal sac, and genital mucosa. Intraorally, rhinosporidiosis is known to involve the lip, palate, and uvula, secondarily, by direct extension from nasal and nasopharyngeal lesions $^{[1]}$. However primary involvement of the parotid duct is extremely rare which prompted us to report. The exact incidence is not reported in any literatures and modem of information is available only in the form of case reports.

\section{Case Report}

An 55 -year-old male reported to the surgery OPD with complaints of swelling on left side of the face since 20 days, associated with a history of sudden increase in its size and occasional pain associated with swelling during chewing of food. There was no history of any trauma or any drug intake in the recent past. On clinical examination, patient was moderately built with no signs of pallor, jaundice, or lymphadenopathy. Systemic examination also did not reveal any abnormalities. The nose, nasopharynx, oropharynx, and eyes appeared normal. On local examination, there was a single, 
soft to firm consistency, discrete extraoral swelling on the left side of the cheek measuring about $4 \times 3 \mathrm{~cm}$, that initially started (infront of tragus) in the parotid region and then extended anteriorly to masseter muscle to involve other portions of the face [Fig 1]. Skin over the swelling was normal in color and texture with no local rise of temperature that ruled out possibility of any cellulitis .The swelling was mildly tender on palpation with no fixity to underlying skin or structure. There was mild restriction of oral movements. Intraoral examination showed no evidence of caries tooth but the patient gave history of tobacco chewing which he had discontinued few months back . Routine laboratory investigation revealed mild eosinophilia (eosinophils 12\%). Ultrasonography (USG) showed a cystic lesion in the subcutaneous plane of cheek in the parotid region of size $3 \times$ $1.6 \mathrm{~cm}$, with echogenic debris and internal septations. With clinical diagnosis of cystic lesion the patient was sent for FNAC to rule out possibility of any malignancy if any, as the swelling was rapidly enlarging and also taking into consideration the age of the patient. FNAC Serous fluid aspirated and smear shows few aggregates of benign epithelial cells and macrophages, compatible with retention cyst, advice to go for an incisional biopsy before undergoing any other major surgeries. Incisional biopsy revealed dilated duct of the parotid gland lined by columnar epithelium with areas of squamous metaplaisa with sub-epithelial dense lympho-plasmacytic infiltration admixed with sporangia of varying sizes containing numerous daughter spores of Rhinosporidium seeberi [Fig 1 (a)(b)(c)(d)]. The surgeons then incised the stenosed intraoral opening of left parotid duct and cannulated the duct and the cyst and sutured it to oral mucosa to keep it in position so that intraoral drainage of left parotid gland secretion was maintained. After complete drainage of the duct the stent was removed after 1 week and the patient was prescribed oral dapsone for 6 months. Patient responded well to Dapsone and within a month his facial swelling decreased in size.

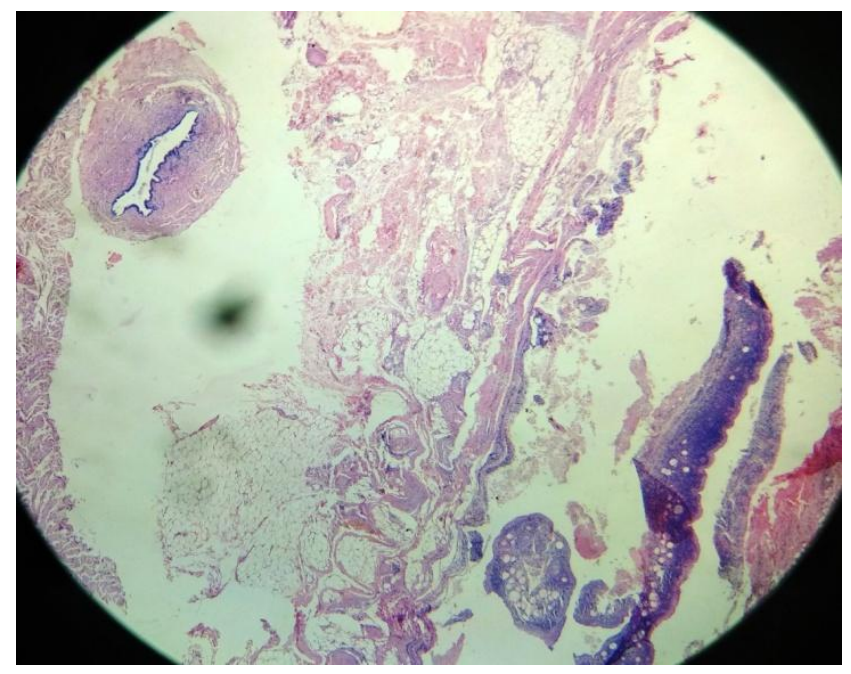

Fig 1 (a) Scanner view 40x -Showing Parotid duct and smooth muscle with fibrofatty areas.

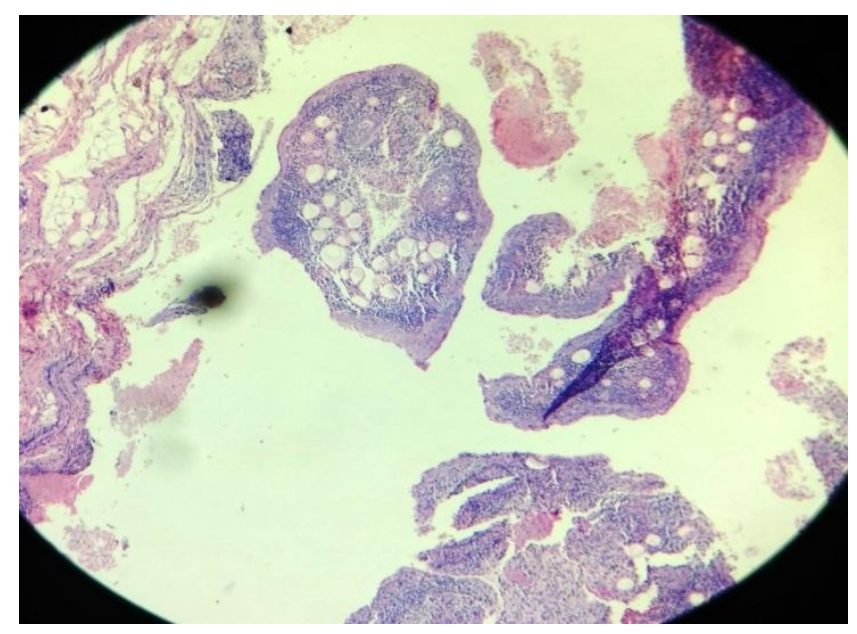

Fig 1 (b) LP 100X- Subepithelial tissue showing good number of spores

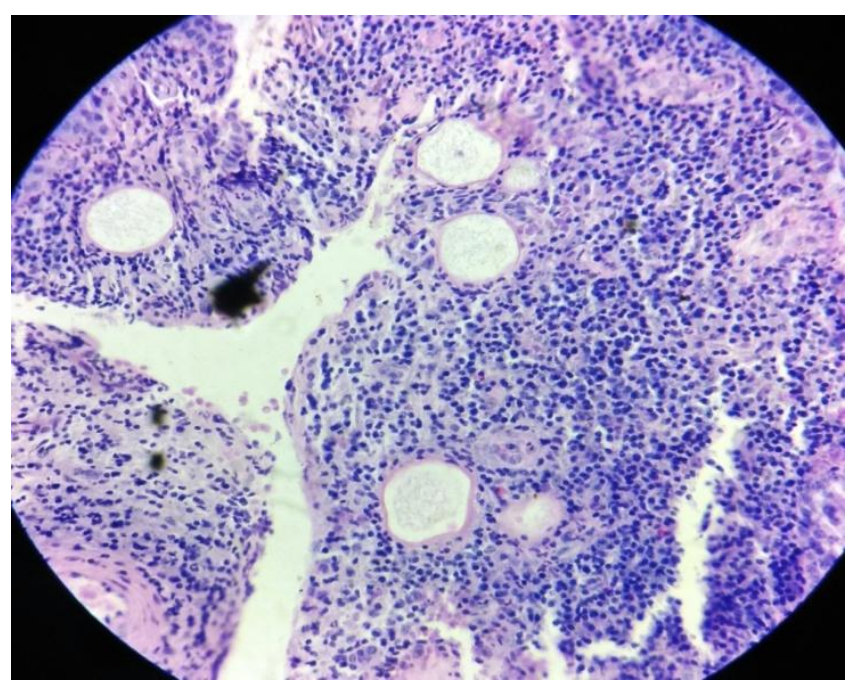

Fig 1 (c) LP100X 


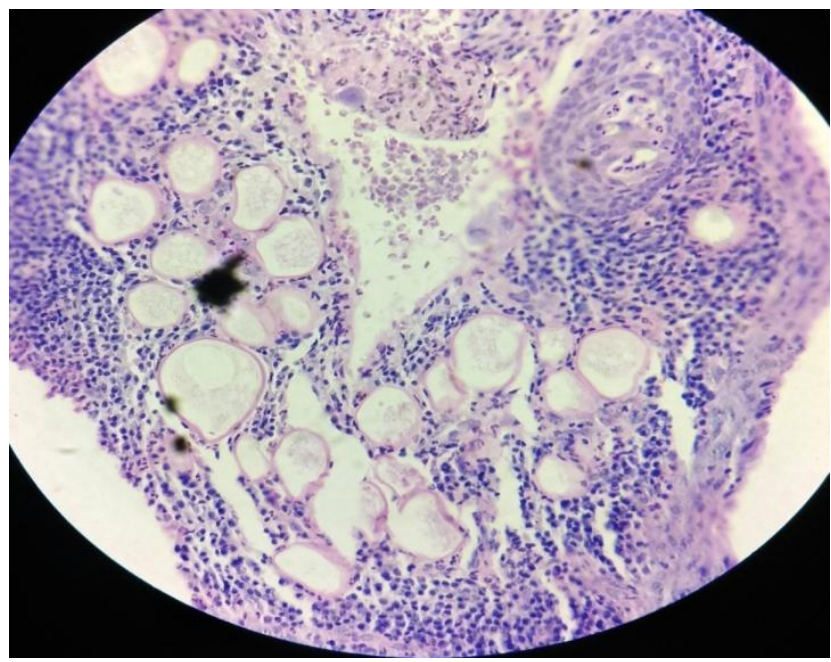

Fig 1 (d) LP100X

Fig 1 (c) (d)-LP100X Showing double walled chitinous walls of Rhinosporidiosis admixed with lymphoplasmacytic infiltrate.

\section{Discussion}

Rhinosporidiosis is a chronic granulomatous infection, predominantly affecting the mucous membrane of humans. Clinically it presents as a polypoidal strawberry like mass, pink to purple in colour studded with white punctuate spots that is highly vascular and easily bleeds on touch. Rhinosporidiosis can occur at any age but commonly encountered between 20 to 35 years, with a slight male predilection [M:F=4:1].

It is unusual unicellular pathogen that is difficult to culture and whose taxonomic classification is also controversial .Previously the causative organism has been considered to be a fungus but now it has been included into a novel group of fish parasites mesomycetozoea (a class of microorganisms intermediate between animals and fungi) based on phylogenetic analysis of Rhinosporidium seeberi's 18 S Small Subunit Ribosomal DNA ${ }^{[5,6]}$.

Majority of the cases occur in upper respiratory tract, notably anterior nares, nasopharynx, larynx, and soft palate .Transepithelial infection through the traumatised epithelium (most commonly through nasal mucosa) is considered the usual mode of infection considering the natural aquatic habitat of this organism ${ }^{[2]}$. Present case of rhinosporidiosis of the parotid could have resulted due to washing mouth and taking bath using infected pond and well water. The natural patulous opening of the parotid duct in the oral cavity could have promoted a quick passage of the spores into the parotid duct causing ductal stenosis and resulting in the development of the cyst. Following diagnosis and on probing the personal history we came to know that the patient was a pond bather and also uses the same water for his routine early morning activities .

The first case of rhinosporidiosis of the parotid duct was reported by Topazian RG in the year $1966^{[7]}$. Involvement of the stensen's duct is rare and only few cases reported in the literature in last 10 -years ${ }^{[8-13]}$. In most of the the published case reports, patients usually presented with a cystic swelling in the cheek and were provisionally diagnosed as stensen's duct cyst $^{[7,8-15]}$. Rhinosporidiosis was not suspected in any of these cases [similar to our case] where it was suspected to be a benign retention cyst of parotid duct. The diagnosis was confirmed only by histopathological examination of the excised tissue from the duct that was sent after incisional biopsy. The mature stage of Rhinosporidium seeberi consists of characteristic large, thickwalled spherical structures with an apical pore called 'sporangia' (50-1000 $\mu \mathrm{m})$ in various stages of maturation containing smaller daughter cells called 'sporangiospores' $(20-80 \mu \mathrm{m})$. The sporangia and sporangiospores of the organism can be highlighted by typical fungal stains such as Gomori Methenamine Silver(GMS), Periodic Acid-Schiff (PAS), and mucicarmine as well as with standard haematoxylin and eosin stain.

Mucicarmine is particularily helpful in differentiating Coccidioidesimmitis as its sporangia and spores do not stain positively ${ }^{[9]}$. Also intrasporangial endospores of R.seeberi are larger and more numerous than in C.immitis ${ }^{[5]}$. Another entity that needs to be mentioned here is Spherulocystic disease or (Myospherulosis) that also resembles the endospores of R.Seeberi. It is ascribed to erythrocytes altered by lipids, the 
altered erythrocytes do not stain with GMS stain that readily stains R.seeberi.

Surgical excision is the treatment of choice in a case of parotid duct rhinosporidiosis, though minimally invasive surgery along with dapsone can be tried in selected cases similar to our case [16]. Drug of choice is dapsone that appears to be promising as it is known to arrest the maturation of the sporangia, accelerate degenerative cases and also promote fibrosis in the stroma, when used as an adjunct to surgery ${ }^{[17]}$. Recurrences are known to occur due to spillage of endospores on the adjacent tissue or incomplete excision. Our patient is doing fairly well after 3 months of dapsone therapy with no bouts of recurrence as of now.

\section{Conclusion}

The purpose of this report is to encourage clinicians to be aware of the differential diagnosis of proliferative growth in the parotid duct, even in those from nonendemic areas . Meticulous work up in such cases and selection of minimally invasive techniques and medications might solve the problem thus helping patients to avoid unnecessary surgical excision as in our case . Histopathologist should also consider a differential diagnosis of rhinosporidiosis during examination of any granulomatous lesions involving the mucous membranes especially in the endemic areas. An adequate follow up is essential in these cases as they are prone for recurrances and widespread fatal dissemination $^{[18]}$.

\section{References}

1. S.N.Jainand P.V.R. Rao,
"Rhinosporidiosis," CurrentOpinion in
Otolaryngology and Head and Neck
Surgery ,vol.6,no.3 ,pp.182-185,1998.

2. O.Lupi,S.K.Tyring, andM.R.McGinnis, “ ${ }^{\mathrm{Tr}}$ opicaldermatology:fungaltropicaldiseases, "Journalof the American Academy of Dermatology ,vol.53 ,no.6 ,pp.931-951, 2005.
3. W.A.E. Karunnaratne, Rhinosporidiosisin Man, Athlone Press, London,UK,1964.

4. C.Satyanarayana,"Rhinosporidiosis with are cord of 255cases, "Acta OtoLaryngologica ,vol.51 ,pp.348-366 , 1960.

5. Arsecularatne SN. Recent advances in rhinosporidiosis and rhinosporidium [1] seeberi. Indian J Med Microbiol. 2002;20:119-31.

6. Herr RA, Ajello L, Taylor JW, Arseculeratne SN, Mendoza L. Phylogenetic Analysis [2] of Rhinosporidium seeberi's 18S SmallSubunit Ribosomal DNA Groups This Pathogen among Members of the Protoctistan Mesomycetozoa Clade. J Clin Microbiol. 1999;37(9):2750-54.

7. Topazian RG, Rhinosporidiosis of Parotid duct. [4] Br J Oral Surg. 1966;4(1):12-15.

8. Rameshkumar A, Gnanaselvi UP, Dineshkumar T, Raghuram PH, Bharanidharan R, Rajkumar K. Rhinosporidiosis Presenting as a Facial Swelling: A Case Report. Journal of International Oral Health: JIOH. 2015;7(2):58-60.

9. Mohapatra M, Banushree CS. Two rare cases of rhinosporidiosis of parotid duct: Case reports and review of literature. Ann Maxillofac Surg. 2014;4(2):234-36.

10. Panda S, Lenka S, Padhiary SK, Sahoo SR, Srivastava G. Rhinosporidiosis in the parotid duct: a rare case report. J Investig Clin Dent. 2013;4(4):271-74.

11. Sudarshan V, Gahine R, Daharwal A, Kujur P, Hussain N, Krishnani C, et al. Rhinosporidiosis of the parotid duct presenting as a parotid duct cyst - a report of three cases. Indian J Med Microbiol. 2012;30(1):108-11.

12. Sivapathasundharam B, Saraswathi TR, Manjunath K, Sriram G. Rhinosporidiosis of parotid duct. Indian J Dent Res. 2009;20:388-89. 
13. Mahapatra S, Tripathi S, Rath G, Mishra G. Rhinosporidiosis of parotid duct: A case report. Indian J Pathol Microbiol. 2007;50:320-22.

14. Kini U, Amirtham U, Shetty SC, Balasubramanya AM. Rhinosporidiosis of the parotid duct cyst: Cytomorphological diagnosis of an unusual extranasal presentation. Diagn Cytopathol. 2001;25:244-47.

15. Chandra K, Ratnakar C, Ramachandran PC, Prakash S. Rhinosporidiosis of the parotid duct. J Laryngol Otol. 1971;85:1083-85.

16. Sulabha AN, Sangamesh NC, Warad N, Ahmad A. Sialocele: An unusual case report and its management. Indian J Dent Res. 2011;22:336-39.

17. Job A, Venkateswaran S, Mathan M, Krishnaswami H, Raman R. Medical therapy of rhinosporidiosis with dapsone. J Laryngol Otol. 1993;107(9):809-12.

18. Padmavathy L ,Rao I L, Selvam S S ,Sahoo C G .Disseminated Cutaneous Rhinosporidiosis in a HIV sero positive patient .Indian J Dermatol Venerol Leprol 2001;67:332-3. 